\title{
A importância dos profissionais de enfermagem na prevenção ao sarampo no Sistema Único de Saúde: uma revisão narrativa
}

The importance of nursing professionals in the prevention of measles in the unified health system: a narrative review

La importancia de los profesionales de enfermería en la prevención del sarampión en el sistema único de salud: una revisión narrativa

Maisa Maria Batista Ludgério ORCID: https://orcid.org/0000-0001-9284-3176

Universidade de Pernambuco, Brasil

E-mail: maisaludgerio000@gmail.com

Mirela Ferreira Pessoa Deodoro ORCID: https://orcid.org/0000-0001-9571-3828 Universidade de Pernambuco, Brasil E-mail:mireladeodoro@gmail.com

Camilla Maria de Araújo Tavares ORCID: https://orcid.org/0000-0002-8580-6198 Universidade de Pernambuco, Brasil E-mail: camiaraujotv@gmail.com Alice Fonseca Pontes ORCID: https://orcid.org/0000-0002-3291-5964 Universidade de Pernambuco, Brasil E-mail: alicepontes136@gmail.com Gabriela Wanderley da Silva ORCID: https://orcid.org/0000-0001-8155-7828 Universidade de Pernambuco, Brasil

E-mail: gabrielawanderley820@gmail.com Kívya de Holanda Leuthier ORCID: https://orcid.org/0000-0001-8111-0241 Universidade de Pernambuco, Brasil E-mail: kivya54@gmail.com

Mayara Santana da Silva ORCID: https://orcid.org/0000-0002-7489-8779

Universidade de Pernambuco, Brasil E-mail: santanasp1998@gmail.com Natália Almeida Rodrigues ORCID: https://orcid.org/0000-0002-6991-9168 Universidade de Pernambuco, Brasil

E-mail: nataliaarodrigues0@gmail.com

Brunna Francisca de Farias Aragão ORCID: https://orcid.org/0000-0002-7186-3108 Universidade de Pernambuco, Brasil

E-mail: brunnafrancisca1999@gmail.com

Beatriz Caetano da Silva

ORCID: https://orcid.org/0000-0002-2641-7686 Universidade de Pernambuco, Brasil

E-mail: beatrizcaetano20001@gmail.com

Sara Rodrigues Cordeiro da Silva ORCID: https://orcid.org/0000-0002-4748-8627 Universidade de Pernambuco, Brasil

E-mail: sararodrigues.sr.sr@gmail.com

Valdeque José Marques Junior ORCID: https://orcid.org/0000-0002-3291-5964 Universidade de Pernambuco, Brasil E-mail: valdeque.marques@upe.br

Letícia Helena Guedes Rodrigues ORCID: https://orcid.org/0000-0002-2581-2879 Universidade de Pernambuco, Brasil E-mail: letisrs2018@gmail.com 


\author{
Luiz Sérgio de Souza Belém Filho \\ ORCID: https://orcid.org/0000-0002-9708-3759 \\ Universidade de Pernambuco, Brasil \\ E-mail: luiz.sergiobelem137@gmail.com \\ Petrúcio Luiz Lins de Morais \\ ORCID: https://orcid.org/0000-0002-1347-2248 \\ Universidade de Pernambuco, Brasil \\ E-mail: petruciomorais@ hotmail.com
}

\begin{abstract}
Resumo
O sarampo pode ser definido como uma doença contagiosa de disseminação pessoa-pessoa através de partículas nasofaríngeas disseminadas no ar e é uma das principais causas de hospitalização de crianças, estando diretamente ligado ao estado nutricional, imunitário e situação socioeconômica do doente. $\mathrm{O}$ objetivo dessa pesquisa foi compreender e analisar a atuação do enfermeiro no sistema único de saúde no controle e prevenção do sarampo. A busca se deu nas bibliotecas: Scientific Electronic Library Online (SciELO), Biblioteca Virtual em Saúde (BVS) e Google Acadêmico, por meio dos Descritores em Ciências da Saúde (DeCS), "Enfermagem" e "Sarampo", e os resultados reportados foram postos em tabela e analisados. Foram identificadas três categorias relacionadas à importância da enfermagem na prevenção ao sarampo: a sua atuação enquanto educadora em saúde, prestando orientações quanto à vacinação; a sua importância para a garantia de uma boa cobertura vacinal e a valorização da capacitação e educação permanente. Pode-se evidenciar a importância da capacitação dos profissionais de enfermagem para realizarem práticas baseadas em evidências e realizarem com maestria o ensino em saúde, reduzindo dessa forma, o número de infecções presentes na sociedade causado pelo sarampo.
\end{abstract}

Palavras-chave: Enfermagem; Sarampo; Sistema Único de Saúde.

\begin{abstract}
Measles can be defined as a contagious disease of person-to-person dissemination through nasopharyngeal particles disseminated in the air and is one of the main causes of hospitalization of children, being directly linked to the nutritional status, immune status and socioeconomic situation of the patient. The objective of this research was to understand and analyze the role of nurses in the Brazilian National Health System in the control and prevention of measles. The search was done in the following libraries: Scientific Electronic Library Online (SciELO), Virtual Health Library (VHL), and Google Scholar, using the Health Science Descriptors (DeCS), "Nursing" and "Measles", and the reported results were tabulated and analyzed. Three categories related to the importance of nursing in measles prevention were identified: its role as a health educator, providing guidance on vaccination, its importance in ensuring good vaccination coverage, and the need for training and continuing education. The importance of training nursing professionals to perform evidencebased practices and to carry out health education with mastery can be evidenced, thus reducing the number of infections in society caused by measles.
\end{abstract}

Keywords: Nursing; Measles; Unified Health System.

\title{
Resumen
}

El sarampión puede definirse como una enfermedad contagiosa de diseminación de persona a persona a través de partículas nasofaríngeas diseminadas en el aire y es una de las principales causas de hospitalización de los niños, estando directamente relacionada con el estado nutricional, el estado inmunitario y la situación socioeconómica del paciente. El objetivo de esta investigación fue conocer y analizar el papel de las enfermeras del Sistema Nacional de Salud de Brasil en el control y la prevención del sarampión. La búsqueda se llevó a cabo en las bibliotecas: Scientific Electronic Library Online (SciELO), Biblioteca Virtual en Salud (BVS) y Google Académico, a través de los Descritores en Ciencias de la Salud (DeCS), "Enfermagem" y "Sarampo", y los resultados reportados fueron puestos en tabla y analizados. Se identificaron tres categorías relacionadas con la importancia de la enfermería en la prevención del sarampión: su papel como educadora sanitaria, proporcionando orientación sobre la vacunación, su importancia para garantizar una buena cobertura de vacunación y la necesidad de formación y educación continua. Se puede evidenciar la importancia de formar a los profesionales de enfermería para que realicen prácticas basadas en la evidencia y para que realicen con maestría la educación sanitaria, reduciendo así el número de infecciones en la sociedad causadas por el sarampión.

Palabras clave: Enfermería; Sarampión; Sistema Único de Salud.

\section{Introdução}

O sarampo pode ser definido como uma doença contagiosa de disseminação pessoa-pessoa através de partículas nasofaríngeas disseminadas no ar através da fala, tosse e espirro. Caracterizado por um quadro febril com o aparecimento de exantemas de pele, o sarampo é uma das principais causas de hospitalização de crianças, estando diretamente ligado ao estado nutricional, imunitário e situação socioeconômica do doente (Xavier, et al., 2019). Causado pelo vírus do gênero Morbillivirus, 
tem seu ápice de transmissão 4 ou 6 dias antes ou depois do aparecimento do exantema, tendo como sintomas a tosse, febre, coriza e as manchas de Koplik, manchas brancas ou azuladas que podem aparecer na mucosa oral um dia antes do exantema e auxiliam no diagnóstico (Branco \& Morgado, 2019).

Por ser uma doença que em sua fisiopatologia atinge principalmente o trato respiratório superior, na infância, o sarampo pode ser facilmente confundido com gripe, dengue e até enteroviroses. Quando acomete o hospedeiro, o vírus rapidamente atinge o sistema linfático seguido por um período de replicação viral e disseminação para outros órgãos como rins e fígado através de linfócitos e monócitos, o que causa imunossupressão no indivíduo, tornando-o suscetível a doenças oportunistas. Sendo assim, o sarampo caracteriza-se como uma doença multissistêmica que tem como principal forma de diagnóstico o exame físico e laboratoriais, como o Ensaio de Imunoadsorção Enzimática (ELISA), que permitem detectar a imunoglobulina M (IgM) para o vírus no plasma sanguíneo (Carvalho, et al., 2019; Xavier, et al., 2019;).

No Brasil, o sarampo é uma doença de notificação compulsória e sua vacina está disponível desde 1963 sendo esta a única forma de prevenir a doença uma vez que não há tratamento específico para o sarampo (Branco \& Morgado, 2019). Para que ocorra de maneira correta e eficaz a vacinação contra o sarampo, o Programa Nacional de Imunização (PNI) recomenda que sejam administradas duas doses da vacina até os 15 meses de idade, sendo a primeira delas a tríplice viral aos 12 meses, que previne contra rubéola, caxumba e sarampo e aos 15 meses a tetraviral, que protege contra o sarampo, rubéola, caxumba e varicela (Carvalho, et al., 2019; Garcia, et al., 2020). Em situações nas quais as pessoas não tenham tomado as duas doses até os 15 meses, indivíduos de 2 a 29 anos tomam duas doses com intervalo de 30 dias, de 30 a 49 anos apenas uma dose e aqueles acima de 49 anos que não tomaram a vacina não precisam mais tomá-la por acreditar-se que não tenham tido contato com o vírus (Garcia, et al., 2020).

O país recebeu, em 2016, da Organização Pan-americana um certificado de eliminação da circulação do vírus do sarampo. Entretanto, de acordo com o boletim epidemiológico do Ministério da Saúde, em 2020 foram notificados 16.104 casos de sarampo no país em 21 estados diferentes e 4 destes com transmissão ativa no país, sendo as crianças menores de 1 ano as mais afetadas, o que fez com que o país perdesse o certificado de eliminação do sarampo (Brasil, 2020). Esse fenômeno ocorre principalmente pela queda na taxa da cobertura vacinal principalmente em crianças, que pode ter sido gerada graças ao sucesso da vacinação e implementação do PNI, uma vez que o não contato das gerações mais novas com doenças anteriormente erradicadas causa a falsa sensação de segurança, resultando numa verdadeira dicotomia (Caetano et al., 2021). Mediante a isso, o Ministério da saúde adotou em 2020 a vacinação indiscriminada para pessoas entre 20 e 49 anos e a dose zero da tríplice viral para crianças entre 6 e 11 meses (Brasil, 2020).

Devido à sua importância no controle das doenças imunopreveníveis, com práticas de promoção, educação em saúde e sua inserção numa lógica territorial, a atenção básica desempenha papel fundamental no controle do sarampo, uma vez que a vacinação é a principal forma de conter a doença. Neste sentido, serviços que garantem melhor estrutura operacional, como salas exclusivas para vacinação, equipamento de refrigeração, caixa térmica e equipe qualificada conseguem garantir maior taxa de cobertura vacinal, por permitirem maior número de atividades extramuros, bem como a inserção do uso de materiais educativos, que oportunizam tanto a educação permanente dos profissionais como a ampliação do conhecimento dos usuários acerca da vacinação e sua importância ( Nascimento, et al., 2021; Vieira, et al., 2020;).

Dentro do contexto da atenção básica, o profissional de enfermagem ganha destaque na prevenção de doenças imunopreveníveis por, dentre todas as suas funções, ter papel fundamental nas práticas de educação em saúde, o que permite a ampliação, a captação e a conscientização da população do território ao qual está inserido quanto à vacinação e sua importância na prevenção do sarampo. Ressalta-se, também, que cabe a este profissional manter sua prática baseada em evidências, atentandose ao cumprimento dos princípios da integralidade, universalidade e equidade do Sistema Único de Saúde (SUS), tornando o ato de vacinar-se menos mecânico e automatizado, respeitando a individualidade dos usuários (Nascimento, et al., 2021). 
Com base nisso, surge o seguinte questionamento: Qual o papel da Enfermagem na prevenção do sarampo? Frente a este questionamento, este trabalho apresenta como objetivo compreender e analisar a atuação do enfermeiro no sistema único de saúde no controle e prevenção do sarampo.

\section{Metodologia}

Trata-se de uma revisão narrativa da literatura, que consiste num tipo de estudo amplo, apropriado para descrever o desenvolvimento de um determinado assunto. Consiste numa categoria de grande importância para a educação continuada, pois permite adquirir conhecimentos e atualizações em um curto espaço de tempo (Rother, 2007). É, portanto, construída sem estabelecer uma metodologia rigorosa (Vosgerau \& Romanowski, 2014). A revisão foi realizada nas seguintes etapas: definição do objetivo e questão norteadora, definição dos critérios de inclusão e exclusão, busca pelos estudos nas plataformas bibliográficas, seleção e elegibilidade dos artigos e análise daqueles que foram incluídos.

A busca se deu nas bibliotecas: Scientific Electronic Library Online (SciELO), Biblioteca Virtual em Saúde (BVS) e Google Acadêmico, por meio dos Descritores em Ciências da Saúde (DeCS), "Enfermagem" e "Sarampo" Foram incluídos estudos publicados no período entre 2016 e 2021, em português, disponíveis na íntegra e que responderam à questão norteadora: "Qual é o papel e a importância dos profissionais de enfermagem na prevenção ao sarampo, segundo os estudos disponíveis na literatura?”. Foram excluídos estudos não disponíveis na íntegra, teses, publicados fora do período selecionado, e que não correspondiam ao tema proposto.

Foram resgatados, por meio da estratégia de busca, 6 artigos na BVS, 5 artigos na SciELO e 20 artigos no google acadêmico. Após aplicação dos critérios de inclusão e exclusão, foram selecionados, finalmente, 8 estudos para a construção da presente revisão. A Figura 1 demonstra a distribuição dos estudos em fluxograma, de acordo com as etapas da revisão:

Figura 1: Fluxograma de artigos encontrados na Revisão Narrativa de Literatura nas bibliotecas BVS, SciELO e Google Acadêmico.

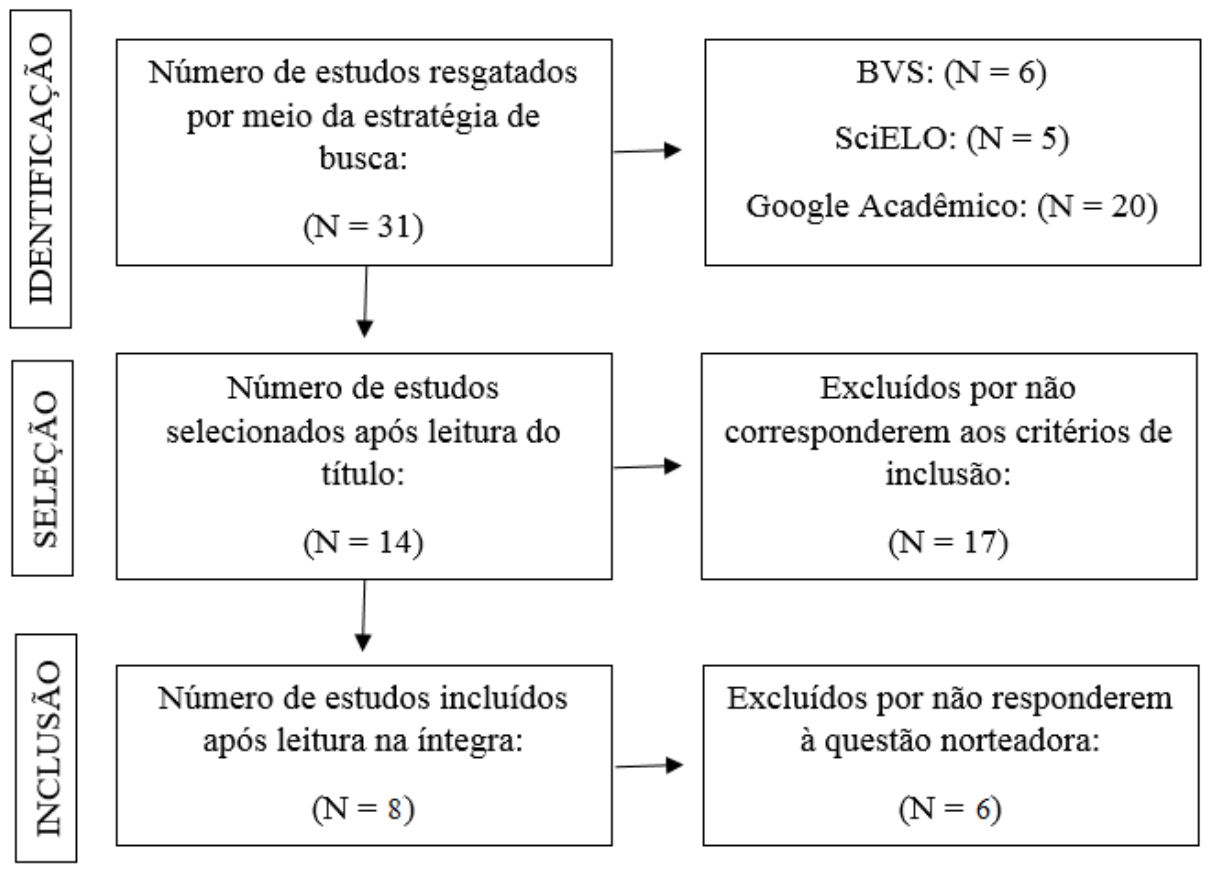

Fonte: Ludgério, et al., (2021). 


\section{Resultados e Discussão}

Esse estudo foi composto por uma amostra final de 8 artigos científicos, usando como critérios de inclusão os estudos que estivessem datados entre 2016 e 2021, no idioma Português, disponíveis na íntegra e que abordassem o papel e a importância dos profissionais de enfermagem na prevenção ao sarampo. Realizou-se a busca nas bibliotecas virtuais Scientific Electronic Library Online (SciELO), Biblioteca Virtual em Saúde (BVS) e Google Acadêmico.

Os 8 artigos selecionados para compor essa revisão foram analisados e detalhados de acordo com a tabela 1 em número, periódico, ano e autoria, título e biblioteca virtual, objetivos e metodologia.

Tabela 1. Principais informações dos artigos selecionados. Recife, Pernambuco, Brasil.

\begin{tabular}{|c|c|c|c|c|}
\hline $\mathbf{N}^{\mathbf{o}}$ & Periódico, ano e autoria & Título e biblioteca virtual & Objetivos & Metodologia \\
\hline 1 & $\begin{array}{l}\text { Revista Nursing, 2020. Andrade, } \\
\text { N. C. M., Costa, R. A., Alves, M. } \\
\text { E. F., Duran, I. O., Siqueira, J. } \\
\text { M., \& Farias, S. N. P }\end{array}$ & $\begin{array}{l}\text { A enfermagem no enfrentamento } \\
\text { do sarampo e outras doenças } \\
\text { imunopreviníveis; BVS. }\end{array}$ & $\begin{array}{l}\text { Averiguar a atuação } \\
\text { profissionais no controle } \\
\text { doenças imunopreveníveis } \\
\text { Atenção Primária em Saúde. }\end{array}$ & Revisão integrativa \\
\hline 2 & $\begin{array}{l}\text { Research, Society and } \\
\text { Development, 2020. Cruz, G. C., } \\
\text { RAIOL, I. F., Silva, V. N. B., } \\
\text { Nascimento, M. H. M., Monteiro, } \\
\text { L. T. D. S., \& Valois, R. C. }\end{array}$ & $\begin{array}{l}\text { Índices da cobertura vacinal do } \\
\text { sarampo no Brasil: revisão } \\
\text { integrativa da literatura; Google } \\
\text { Acadêmico. }\end{array}$ & $\begin{array}{l}\text { Analisar as produções científicas } \\
\text { quanto aos índices de cobertura } \\
\text { vacinal do sarampo } \\
\text { no Brasil no período de } 2015 \text { a } \\
2019 \text {. }\end{array}$ & Revisão integrativa \\
\hline 3 & $\begin{array}{l}\text { Revista de } \quad \text { Enfermagem } \\
\text { Referência, 2019. Frade, J. M. G., } \\
\text { Henriques, C. M. G., \& Frade, F. }\end{array}$ & $\begin{array}{l}\text { Registros vacinais de } \\
\text { enfermagem: importância para } \\
\text { vigilância da saúde das } \\
\text { populações; Google Acadêmico. }\end{array}$ & $\begin{array}{l}\text { Avaliar a fiabilidade e precisão } \\
\text { dos registos vacinais de } \\
\text { enfermagem relativos à estratégia } \\
\text { vacina antissa- } \\
\text { rampo, parotidite e rubéola } \\
\text { (VASPR). }\end{array}$ & Estudo transversal \\
\hline 4 & $\begin{array}{l}\text { Revista da Sociedade Brasileira } \\
\text { de Enfermeiros Pediatras, } 2019 . \\
\text { Gaíva, M. A. M., Alves, M. D. S. } \\
\text { M., \& Monteschio, C. A. C. }\end{array}$ & $\begin{array}{l}\text { Consulta de enfermagem em } \\
\text { puericultura na estratégia saúde } \\
\text { da família; Google Acadêmico. }\end{array}$ & $\begin{array}{l}\text { Analisar as ações desenvolvidas } \\
\text { pelo enfermeiro na consulta de } \\
\text { puericultura à criança, em } \\
\text { unidades de } \\
\text { saúde da família. }\end{array}$ & $\begin{array}{l}\text { Pesquisa descritiva com } \\
\text { abordagem qualitativa }\end{array}$ \\
\hline 5 & $\begin{array}{l}\text { Electronic Journal Collection } \\
\text { Health, 2020. Gomes, Y., } \\
\text { Ferreira, A. M. R., Boulhosa, M. } \\
\text { R. Moreira, L. C. S., Carneiro, R. } \\
\text { R., Vasconcelos, L. A., Bentes, } \\
\text { A. L. G., Sena, E. M. M., } \\
\text { Oliveira, E. M., \& Oliveira, J. G. }\end{array}$ & $\begin{array}{l}\text { Educação em saúde em um } \\
\text { centro de saúde escola acerca da } \\
\text { prevenção ao sarampo: um relato } \\
\text { de experiência; Google } \\
\text { Acadêmico. }\end{array}$ & $\begin{array}{l}\text { Relatar a experiência de } \\
\text { acadêmicos de um curso de } \\
\text { graduação em enfermagem acerca } \\
\text { de uma } \\
\text { atividade de educação em saúde } \\
\text { sobre sarampo. }\end{array}$ & Relato de experiência \\
\hline 6 & $\begin{array}{l}\text { Acta. Paul. Enferm, } 2020 . \\
\text { Medeiros, E. A. S. }\end{array}$ & $\begin{array}{l}\text { Entendendo o ressurgimento e o } \\
\text { controle do sarampo no Brasil; } \\
\text { Scielo. }\end{array}$ & $\begin{array}{l}\text { Discorrer sobre o ressurgimento } \\
\text { do sarampo e as medidas de } \\
\text { controle. }\end{array}$ & Editorial \\
\hline 7 & $\begin{array}{l}\text { Saúde Coletiva, 2018. Peixoto, } \\
\text { M. S. B. F., Andrade, M., \& Paz, } \\
\text { E. P. A. }\end{array}$ & $\begin{array}{l}\text { Cobertura vacinal e sarampo no } \\
\text { Brasil: uma revisão integrativa; } \\
\text { Google Acadêmico. }\end{array}$ & $\begin{array}{l}\text { Sistematizar o co- } \\
\text { nhecimento produzido sobre o } \\
\text { sarampo no } \\
\text { país a partir dos anos } 2010 \text {. }\end{array}$ & Revisão integrativa \\
\hline 8 & $\begin{array}{l}\text { Revista Referências em Saúde da } \\
\text { Faculdade Estácio de Sá de } \\
\text { Goiás, 2020. Santos, E. A. M., } \\
\text { Melo, S. R., Bandeira, S. R. } \\
\text { Costa, C. S. C., Santana, T. S., } \\
\text { Leal, L. G., Pitangueira, C. M. F. } \\
\text { C., \& Celestino, K. A. A. }\end{array}$ & $\begin{array}{l}\text { Atuação do enfermeiro na } \\
\text { hesitação e recusa vacinal; } \\
\text { Google Acadêmico. }\end{array}$ & $\begin{array}{l}\text { Identificar a atuação } \\
\text { do enfermeiro na hesitação e } \\
\text { recusa vacinal, a } \\
\text { importância da imunização e da } \\
\text { educação em saúde } \\
\text { realizada pelo enfermeiro. }\end{array}$ & Estudo bibliográfico \\
\hline
\end{tabular}

Fonte: Ludgério, et al., (2021). 
A partir da análise dos estudos selecionados, foi possível identificar três categorias relacionadas à importância da enfermagem na prevenção ao sarampo. A primeira relaciona-se ao seu papel enquanto educadora em saúde, prestando orientaç̃es quanto à vacinação, enquanto a segunda destaca a sua importância para a garantia de uma boa cobertura vacinal e a terceira aponta para a necessidade de capacitação e educação permanente.

\section{Educação em saúde e orientações quanto à vacinação}

Para Viegas, et al., (2019), o compartilhamento de conhecimento sobre a relevância da imunização, das doenças transmissíveis e as que são imunopreveníveis proporciona um processo de transformação social e ampliação da cobertura vacinal. Assim, o estudo de Andrade, et al., (2020) aponta que a educação em saúde realizada pelos enfermeiros, especialmente no contexto da vacinação, é de grande importância, pois, em virtude do vínculo entre tais profissionais e a comunidade, faz com que o cliente seja entendido como fator essencial no processo de saúde, concedendo autonomia e incentivando o autocuidado. Cruz, et al. (2020) concordam com tal colocação, afirmando que a educação em saúde é essencial para a prevenção, sendo a sua ausência um fator estrutural de agravamento do atraso vacinal, juntamente com a falta de participação nas campanhas, a adesão da população aos serviços e as oportunidades perdidas de vacinação.

Nesse contexto, Gomes, et al., (2020) traz em seu relato de experiência as orientações quanto à vacinação contra o sarampo na sala de espera como uma boa estratégia de educação em saúde, enfatizando a vacina como a principal forma de prevenção. Santos, et al., (2020) apontam, ainda, o momento de hesitação e recusa vacinal como ideal para a prestação de tais orientações, sendo um método facilitador para criar um elo entre a comunidade e os serviços de saúde.

\section{Importância da enfermagem para uma boa cobertura vacinal}

Domingues, et al., (2019) afirma que as estratégias para reverter a redução das coberturas vacinais devem considerar os diversos fatores que contribuem para essa situação. Por isso, além da educação em saúde, os estudos também citaram outras ações de enfermagem de grande importância para o sucesso da cobertura vacinal. Andrade, et al., (2020) destaca a importância da enfermagem na Atenção Primária à Saúde (APS), que, além das orientações, também atua na atualização do cartão de vacina dos usuários, contribuindo para a erradicação e controle de doenças imunopreveníveis em sua área de abrangência. O estudo de Gaíva e Monteschio., (2019) contribui ao destacar que a consulta de enfermagem em puericultura permite a avaliação do calendário vacinal da criança e abre a possibilidade de realização da educação em saúde.

Cruz, et al., (2020) trazem, ainda, a busca ativa realizada pelos enfermeiros dos usuários que estão em atraso, principalmente as crianças. Os autores também destacam que o profissional de enfermagem que atua em sala de vacina tem a possibilidade de intervir no processo de saúde doença, estimulando o usuário a adotar comportamentos saudáveis e participativos. Nesse contexto, Frade e Frade., (2019) identificaram, também, a importância dos registros vacinais de enfermagem, que ajudam na produção de indicadores de monitorização e vigilância epidemiológica, garantindo o sucesso dos planos de vacinação. Por fim, Peixoto e Paz (2018) afirmam que, para além da administração dos imunobiológicos e da educação em saúde, a enfermagem se destaca no acolhimento dos clientes e na realização de uma prática assistencial segura e de qualidade.

\section{Valorização da capacitação e educação permanente}

Também foi apontada nos estudos a importância de capacitação e educação permanente para os profissionais. Andrade, et al., (2020) destaca que a Educação Continuada em Saúde (ECS) implica na atualização profissional e aquisição de conhecimentos pertinentes à sua prática. O estudo também aponta que a EPS pode proporcionar um maior planejamento das ações, minimizando as oportunidades perdidas de vacinação, sendo um elemento fundamental para contribuir com a transformação das práticas do SUS. 
Dentro desse contexto, Lemos (2016) define a EPS como uma estratégia de garantia da universalidade, com a promoção de qualidade de vida para usuários e trabalhadores, devendo se dar não apenas no cotidiano, mas nos espaços políticos e nas articulações coletivas. Assim, fica evidente a sua importância para a garantia de uma atuação efetiva, tanto da enfermagem quanto para todo o sistema de saúde.

\section{Conclusão}

Mediante a análise dos estudos, através dos achados na leitura, os artigos selecionados corroboram que diante do atual cenário da saúde pública brasileira, a vacina apresenta-se como a estratégia mais eficaz na prevenção do sarampo, doença sem tratamento específico e altamente contagiosa. Prova disso, são os números decrescentes de casos de sarampo desde o início da aplicabilidade vacinal contra essa doença e a inserção da tríplice viral e tetra viral no calendário de vacinação brasileiro.

O sarampo, como uma doença infecciosa aguda transmissível e altamente contagiosa, possui uma demanda maior por parte da saúde pública com medidas amplas e mais rigorosas quanto ao sistema vacinal do indivíduo, pensando nele como membro pertencente a uma comunidade e prezando pela segurança de todos. Vale lembrar, que o Brasil por muitos anos teve a doença como protagonista de grandes epidemias, as quais ocasionaram altos índices de mortalidade.

É indubitavelmente, a necessidade de averiguar a capacitação dos profissionais de enfermagem para possuírem como uma de suas aplicabilidades a participação direta na conscientização referente à importância vacinal diante da eficácia contra agentes patógenos presentes no ambiente. Em virtude disso, salienta-se a importância de enfatizar seu papel diante da educação em saúde desde os primórdios da vida do indivíduo. E como isso, é observado no ambiente de consulta da puericultura a análise criteriosa do calendário vacinal e prevenção de doenças como o sarampo. Outrossim, fica evidente a importância do reconhecimento do benefício vacinal no âmbito do autocuidado em saúde, devendo-se capacitar cada vez mais os profissionais de enfermagem para realizarem práticas baseadas em evidências e realizarem com maestria o ensino em saúde, reduzindo dessa forma, o número de infecções pelo vírus do sarampo no Brasil.

Em suma, destaca-se a precariedade de trabalhos voltados à valorização vacinal contra o sarampo,tendo em vista a diminuição de crianças vacinadas, como observado no surto de sarampo em Roraima e no Amazonas em 2017. Sendo necessário a análise dos motivos pelo qual a população não está se vacinando e consequentemente as questões referentes à saúde pública envolvida.

\section{Referências}

Andrade, N. C. M., Costa, R. A., Alves, M. E. F., Duran, I. O., Siqueira, J. M., \& Farias, S. N. P. (2020). A enfermagem no enfrentamento do sarampo e outras doenças imunopreviníveis. Revista Nursing; 23(263):3721-28.

Branco, V. G. C., \& Morgado, F. E. F. (2019). O surto de sarampo e a situação vacinal no Brasil. Revista de Medicina de Família e Saúde Mental; 1(1):74-88.

Brasil, M. S. (2020). Boletim epidemiológico 42. Secretaria de Vigilância em Saúde; 51(42):1-27. https://www.gov.br/saude/pt-br/coronavirus/boletinsepidemiologicos/boletim-epidemiologico-covid-19-no-42.pdf

Caetano, M. B. L., Lisbôa, J. V. C. O., Fermoseli, A. F. O., \& Oliveira, J. S. (2021). Reincidência epidêmica do sarampo no Brasil como consequência da pouca adesão popular à vacinação. Ciências Biológicas e de Saúde Unit; 7(1):149-58.

Carvalho, A. L., Dorabela, A., Andrade, J. G., Diniz, L. M. O., \& Romanelli, R. M. C. (2019). Sarampo: atualizações e reemergência.Revista Médica de Minas Gerais; 29(13):80-85.

Cruz, G. C., RAIOL, I. F., Silva, V. N. B., Nascimento, M. H. M., Monteiro, L. T. D. S., \& Valois, R. C. (2020). Índices da cobertura vacinal do sarampo no Brasil: revisão integrativa da literatura. Research, Society and Development; 9(12):1-18.

Domingues, C. M. A. S., Fantinato, F. F. S. T., Duarte, E., \& Garcia, L. P. (2019). Vacina Brasil e estratégias de formação e desenvolvimento em imunizações. Epidemiol. Serv. Saúde; 28(2):1-4.

Frade, J. M. G., Henriques, C. M. G., \& Frade, F. (2019). Registros vacinais de enfermagem: importância para vigilância da saúde das populações. Revista de Enfermagem Referência; 4(20):107-16. 
Gaíva, M. A. M., Alves, M. D. S. M., \& Monteschio, C. A. C. (2019). Consulta de enfermagem em puericultura na estratégia saúde da família. Revista da Sociedade Brasileira de Enfermeiros Pediatras; 19(2):65-73.

Garcia, L. R., Menezes, L. M. S., Jesus, A. B., Souza, I. M., Corrêa, K. L. D., Marques, L. R., Alves, E. A. C., \& Pimentel, C. P. (2020). A importância da vacinação no combate ao sarampo. Brazilian Journal of Health Review; 3(6):16849-57.

Gomes, Y., Ferreira, A. M. R., Boulhosa, M. R. Moreira, L. C. S., Carneiro, R. R., Vasconcelos, L. A., Bentes, A. L. G., Sena, E. M. M., Oliveira, E. M., \& Oliveira, J. G. (2020). Educação em saúde em um centro de saúde escola acerca da prevenção ao sarampo: um relato de experiência. Electronic Journal Collection Health; 12(9):1-5.

Lemos, C. L. S. (2016). Educação permanente em saúde no Brasil: educação ou gerenciamento permanente? Ciência \& Saúde Coletiva; 21(3):913-22.

Medeiros, E. A. S. (2020). Entendendo o ressurgimento e o controle do sarampo no Brasil. Acta. Paul. Enferm; 33(1):1-4.

Nascimento, C. C. L., Monteiro, D. S., Rodrigues, I., L., A., Pereira, A., A., Nogueira, L., M., V., \& Santos, F., V. (2021). Enfermagem em foco; $12(2): 305-11$.

Peixoto, M. S. B. F., Andrade, M., \& Paz, E. P. A. (2018). Cobertura vacinal e sarampo no Brasil: uma revisão integrativa. Saúde Coletiva; 8(45):1-7.

Rother, E. T. (2007). Revisão sistemática x revisão narrativa. Acta. Paul. Enferm; 20(2):1-2.

Santos, E. A. M., Melo, S. R., Bandeira, S. R. Costa, C. S. C., Santana, T. S., Leal, L. G., Pitangueira, C. M. F. C., \& Celestino, K. A. A. (2020). Atuação do enfermeiro na hesitação e recusa vacinal. Revista Referências em Saúde da Faculdade Estácio de Sá de Goiás; 3(2):193-97.

Viegas, S. M. F., Sampaio, F. C., Oliveira, P. P., Lanza, F. M., Oliveira, V. C., \& Santos, W., J. (2019). A vacinação e o saber do adolescente: educação em saúde e ações para a imunoprevenção. Ciência \& Saúde Coletiva; 24(2):351-60.

Vieira, E. W., Pimenta, A. M., Montenegro, L. C., \& Silva, T. M. R. (2020). Estrutura e localização dos serviços de vacinação influenciam a disponibilidade da tríplice viral no Brasil. Revista Mineira de Enfermagem; 24(1325):1-6.

Vosgerau, D. S. R., \& Romanowski, J. P. (2014). Estudos de revisão: implicações conceituais e metodológicas. Rev. Diálogo Educ.; 14(41):165-89.

Xavier, A. R., Rodrigues, T. S., Santos, L. S., Lacerda, G. S., \& Kanaan, S. (2019). Diagnóstico clínico, laboratorial e profilático do sarampo no Brasil. Jornal Brasileiro de Patologia e Medicina Laboratorial. 55(4):390-401. 